ARTICLE

\title{
Formation of metallic cation-oxygen network for anomalous thermal expansion coefficients in binary phosphate glass
}

Yohei Onodera ${ }^{1,2}$, Shinji Kohara $2,3,4,5$, Hirokazu Masai ${ }^{6, \dagger}$, Akitoshi Koreeda $^{7}$, Shun Okamura ${ }^{6}$ \& Takahiro Ohkubo 8

Understanding glass structure is still challenging due to the result of disorder, although novel materials design on the basis of atomistic structure has been strongly demanded. Here we report on the atomic structures of the zinc phosphate glass determined by reverse Monte Carlo modelling based on diffraction and spectroscopic data. The zinc-rich glass exhibits the network formed by $\mathrm{ZnO}_{x}$ (averaged $x<4$ ) polyhedra. Although the elastic modulus, refractive index and glass transition temperature of the zinc phosphate glass monotonically increase with the amount of $\mathrm{ZnO}$, we find for the first time that the thermal expansion coefficient is very sensitive to the substitution of the phosphate chain network by a network consisting of $\mathrm{Zn}-\mathrm{O}$ units in zinc-rich glass. Our results imply that the control of the structure of intermediate groups may enable new functionalities in the design of oxide glass materials.

\footnotetext{
${ }^{1}$ Research Reactor Institute, Kyoto University 2-1010 Asashiro-nishi, Kumatori-cho, Sennan-gun 590-0494, Japan. ${ }^{2}$ Light/Quantum Beam Field, Research Center for Advanced Measurement and Characterization, National Institute for Materials Science (NIMS), 1-1-1 Kouto, Sayo-cho, Sayo-gun 679-5148, Japan. 3 Information Integrated Materials Design Field, Center for Materials Research by Information Integration, NIMS, 1-2-1 Sengen, Tsukuba 305-0047, Japan. ${ }^{4}$ PRESTO, Japan Science and Technology Agency, 7 Gobancho, Chiyoda-ku, Tokyo 102-0076, Japan. ${ }^{5}$ Research and Utilization Division, Japan Synchrotron Radiation Research Institute/SPring-8, 1-1-1 Kouto, Sayo-cho 679-5198, Japan. ${ }^{6}$ Institute for Chemical Research, Kyoto University, Gokasho, Uji 611-0011, Japan. ${ }^{7}$ Department of Physical Sciences, Ritsumeikan University, 1-1-1 Nojihigashi, Kusatsu 525-8577, Japan. ${ }^{8}$ Graduate School \& Faculty of Engineering, Chiba University, 1-33, Yayoi-cho, Chiba 263-8522, Japan. †Present address: Department of Materials and Chemistry, National Institute of Advanced Industrial Science and Technology (AIST), 1-8-31 Midorigaoka, Ikeda, Osaka 563-8577, Japan. Correspondence and requests for materials should be addressed to S.K. (email: KOHARA.Shinji@nims.go.jp) or to H.M. (email: hirokazu.masai@aist.go.jp)
} 
O xide glass prepared by melt-quenching is usually composed of network former (NWF) and network modifier (NWM) groups ${ }^{1}$. $\mathrm{SiO}_{2}$ is a typical NWF oxide that constitutes the ring structures, which are formed from $\mathrm{SiO}_{4}$ tetrahedra ${ }^{2}$. Alkali silicate glass consisting of an alkali oxide as NWM and $\mathrm{SiO}_{2}$ as NWF is a representative oxide glass and it is widely used in industrial applications such as photonic and electronic devices. Furthermore, structural modification of the $\mathrm{SiO}_{4}$ tetrahedral network in alkali silicate glasses has been extensively studied both experimentally and theoretically ${ }^{3-6}$ to clarify structure-property relations of glasses.

$\mathrm{P}_{2} \mathrm{O}_{5}$ is generally classified as NWF groups along with $\mathrm{SiO}_{2}$, $\mathrm{B}_{2} \mathrm{O}_{3}$ and $\mathrm{GeO}_{2}$ from the viewpoint of glass-forming ability. However, $\mathrm{P}_{2} \mathrm{O}_{5}$ differs from other NWF oxides since the $\mathrm{P}=\mathrm{O}$ bond allows the delocalized electrons in phosphate glasses ${ }^{7-10}$. On the other hand, several studies have shown that the main glass network $^{11,12}$ of non-conventional phosphate glass, that is, socalled invert glass, is composed of a counter metal oxide. Previous studies have suggested that the local structure of the $\mathrm{PO}_{4}$ unit does not always act as a NWF, and that its structure depends on the chemical composition of the glass. However, the detailed structure of the glass network has not been fully understood due to the lack of experimental information, which, in turn, is the result of disorder. Phosphate glass is often considered for practical applications because of its durability ${ }^{13}$, but has significant potential for application to several other uses, owing to its unique physical and structural properties ${ }^{14-18}$. Understanding the network structure of a phosphate glass system is therefore one of the most important unresolved issues facing glass science.

In contrast to the conventional NWF group, several metal oxides, which are classified as intermediate groups, can act as either NWF or NWM groups ${ }^{1}$, depending on the number of NWF units, that is, the glass composition. This suggests that the conventional glass-forming theory cannot explain the behaviour of the intermediate group of oxide glass. Zinc oxide is classified as being part of the intermediate group. In the case of zinc phosphate (ZP), monolithic bulk glass can be obtained although the $\mathrm{P}_{2} \mathrm{O}_{5}$ content is $<33.3 \mathrm{~mol} \%$ (that is, less than that of pyro-ZP). ZP exhibits low-melting-point properties and does not contain any hazardous cations, such as lead. Therefore, ZP glass is a promising material for use as lead-free sealing glass ${ }^{19,20}$. Recently, ZP glass has also been shown to be a good host for emitting centres ${ }^{21-24}$ and is, therefore, a potential candidate for next-generation optical materials. In fact, these types of glass exhibit high transparency in the ultraviolet region; for example, the $60 \mathrm{ZnO}-40 \mathrm{P}_{2} \mathrm{O}_{5}$ glass has an optical absorption edge of over $6 \mathrm{eV}$, which stems from the $\mathrm{O}-\mathrm{Zn}$ charge transfer transition ${ }^{25}$. The bandgap of ZP glass is, however, much wider than expected especially when that (at $3.4 \mathrm{eV}$ ) of the wurtzite $\mathrm{ZnO}$ crystal with $\mathrm{Zn}-\mathrm{O}$ four coordination is considered ${ }^{26}$. The four-coordinated state of $\mathrm{Zn}$ is believed to result from its having a similar coordination to that of the $\mathrm{ZnO}$ crystal. The structure of $\mathrm{ZP}$ glass, particularly that of $60 \mathrm{ZnO}-40 \mathrm{P}_{2} \mathrm{O}_{5}$, has been extensively analysed using X-ray photoelectron spectroscopy ${ }^{27,28},{ }^{31} \mathrm{P}$ nuclear magnetic resonance $(\mathrm{NMR})^{29-31}$, X-ray or neutron diffraction $^{32-34}$, high-performance liquid chromatography analysis ${ }^{35}$, Raman and infrared spectroscopy ${ }^{36}$, as well as molecular dynamics simulation ${ }^{37}$. Several groups have also performed structural analyses using neutron and X-ray diffraction with the aid of reverse Monte Carlo (RMC) modelling $34,38,39$. Those studies revealed the zinc in the $\mathrm{ZP}$ glass to be in the four-coordinated state.

However, previous investigations have shown that metal oxide has a small oxygen coordination in glass ${ }^{40-43}$, since the rigid glass network enables the metastable species of metal oxide to be sustained in the glass matrix. Therefore, the modelling of a reliable atomic arrangement in glass based on metal-cationspecific experimental data and conventional diffraction data is essential. As such, in this article, we report on the reliable atomic configuration of $\mathrm{ZP}$ glass from the viewpoint of threedimensional (3D) network linkage, that is, the connectivity of each oxide. We use a combination of ${ }^{31} \mathrm{P}$ magic angle spinning (MAS) NMR, Zn K-edge extended X-ray absorption fine structure (EXAFS), as well as X-ray and neutron diffraction data ${ }^{38}$ to determine the dependence of this connectivity on the chemical composition and on the zinc coordination. Moreover, we discuss the relationship between several properties and glass structure and find that the thermal expansion coefficient is sensitive to the substitution of the phosphate chain network by a network consisting of $\mathrm{Zn}-\mathrm{O}$ units in zinc-rich glass.

\section{Results}

Sample characterization and physicochemical properties. First of all, it is ensured that nanocrystallites are not precipitated in transparent $x \mathrm{ZnO}-(100-x) \mathrm{P}_{2} \mathrm{O}_{5}(x \mathrm{ZP})$ glass prepared by the meltquench method. The chemical compositions of $\mathrm{ZP}$ glasses were determined by using inductively coupled plasma-atomic emission spectrometry analysis (Supplementary Fig. 1 and Supplementary Table 1). It is confirmed that the compositions of our samples are precise. Supplementary Table 2 summarizes the glass transition temperature $T_{\mathrm{g}}$, density, molar volume, refractive indices and the longitudinal sound velocity $V_{\mathrm{L}}$ of $\mathrm{ZP}$ glass. As the table indicates, the $T_{\mathrm{g}}$, density and refractive index increase with the amount of ZnO. Supplementary Fig. 2 shows that the longitudinal modulus $c_{11}$ also increases with the amount of $\mathrm{ZnO}$, while the molar volume decreases.

Figure 1a shows the thermal expansion curves for 58ZP, 60ZP, $65 \mathrm{ZP}$ and 70ZP glass. The bending points of the curves correspond to the $T_{\mathrm{g}}$ listed in Supplementary Table 2. Figure $1 \mathrm{~b}$ shows linear thermal expansion coefficients of these glasses as a function of $\mathrm{ZnO}$ amount. The thermal expansion coefficients increase with increasing $\mathrm{ZnO}$ fraction. If the glass network is similar, that is, if the glass has the same NWF, the lower $T_{\mathrm{g}}$ glass generally exhibits a higher thermal expansion coefficient ${ }^{44,45}$. However, the obtained results show that the higher $T_{\mathrm{g}}$ glass exhibits a higher thermal expansion coefficient. The anomaly of thermal expansion coefficients suggests that the glass networks might be changed, although the $T_{\mathrm{g}}$ and $c_{11}$ values changed linearly depending on the chemical composition (Supplementary Table 2).

NMR spectroscopy and EXAFS. NMR spectroscopic measurements were used to obtain the information on the local structure in glasses. The ${ }^{31} \mathrm{P}$ MAS NMR spectra of $x \mathrm{ZP}$ glass (Fig. 2a) exhibit peaks that correspond to the $\mathrm{Q}^{0}$ (3 p.p.m.), $\mathrm{Q}^{1}$ (-11 p.p.m.) and $\mathrm{Q}^{2}$ (-30 p.p.m.) units, which are commonly observed in ZP glass ${ }^{29-31,46}$. However, peaks corresponding to the $\mathrm{Q}^{3}$ unit are absent from the spectra. The ratio of $\mathrm{Q}^{n}$ units, as calculated from the area of each peak, shows (Fig. 2b) that the number of $\mathrm{Q}^{2}$ chains decreases significantly as the amount of $\mathrm{ZnO}$ increases. The results of our NMR are in line with the results of high-performance liquid chromatography analysis ${ }^{35}$, indicating that the $\mathrm{PO}_{4}$ units no longer form a glass network, especially for 70ZP glass, as was recently suggested by Hoppe et al. ${ }^{39}$.

We also determined the $\mathrm{Zn}-\mathrm{O}$ coordination number and subsequently the local oxygen coordination of zinc. The EXAFS spectra, $k^{3} \chi(k)$, of the different types of ZP glass are shown in Fig. 3a. As the figure shows, the oscillation and the period of the oscillation are slightly attenuated at high $k$ values and shift 

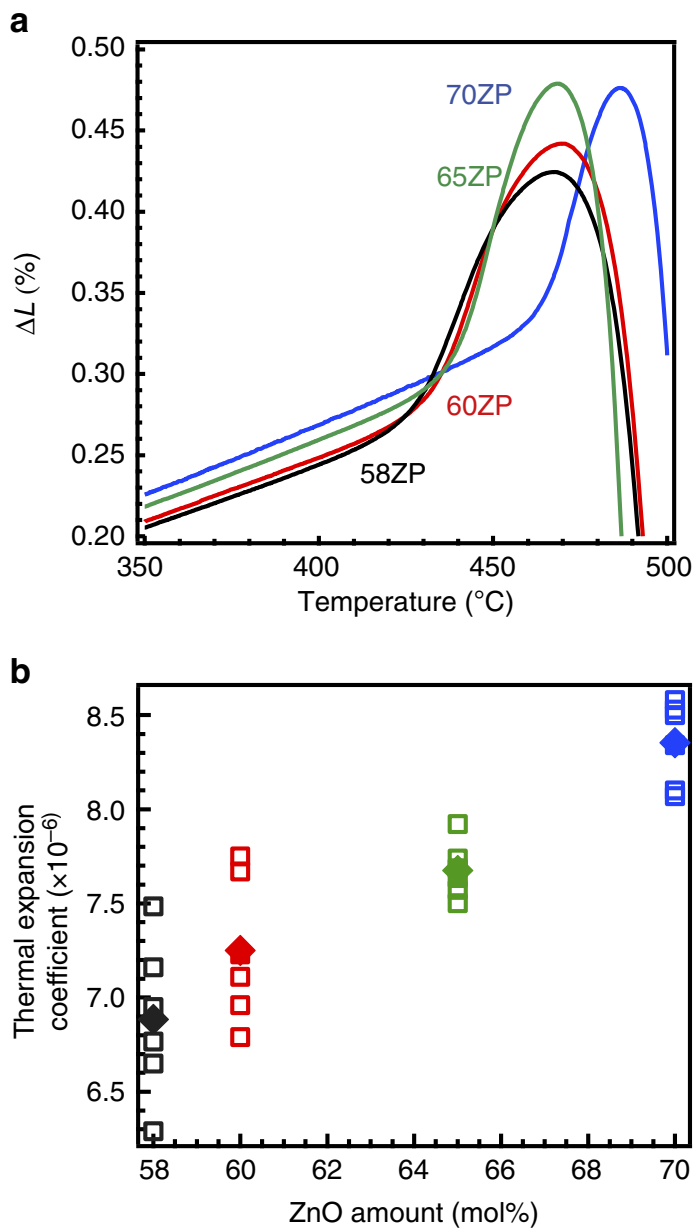

Figure 1 | Linear thermal expansion coefficients of the ZP glass.

(a) Thermal expansion curves of 58ZP, 60ZP, 65ZP and 70ZP glasses.

(b) Thermal expansion coefficients below the $T_{\mathrm{g}}$ as a function of $\mathrm{ZnO}$. The 70ZP glass exhibits higher $T_{g}$ as well as higher thermal expansion coefficient below and above the $T_{\mathrm{g}}$ compared to those of 60ZP glass.

Closed squares indicate each mean value.

towards the low $k$ region as the amount of $\mathrm{ZnO}$ increases. The Fourier-transformed (FT) EXAFS spectra of the $x \mathrm{ZP}$ glass, shown in Fig. 3b, exhibit one prominent peak, that is, the peak corresponding to the first coordination of the glass. Supplementary Table 3 summarizes the atomic distance and Debye-Waller factor, coordination number, $\mathrm{N}_{\mathrm{ZnO}}$, of the $\mathrm{Zn}-\mathrm{O}$ in the glass. We estimated the values by fitting the first coordination shell in the EXAFS spectra and obtained an atomic distance and $N_{\mathrm{ZnO}}$ of $\sim 1.96-1.97 \AA$ and $<4$, respectively. This small oxygen coordination is different from those obtained from X-ray and neutron diffraction with the aid of RMC modelling ${ }^{34,38,39}$.

Structure modelling. We performed RMC modelling using X-ray diffraction, neutron diffraction ${ }^{38}$ and EXAFS data with several coordination number constraints to identify several chemical coordination states around phosphorus, based on the results of ${ }^{31} \mathrm{P}$ MAS NMR, to reveal the behaviour of the oxygen coordination around zinc. Figure 4 shows that there is good agreement between the RMC-modelled and experimentally determined X-ray and neutron structure factors, $S(Q)$ and EXAFS $k^{3} \chi(k)$, of the 60ZP and the 70ZP glasses. The partial structure factors, $S_{i j}(Q)$, calculated from the RMC models are shown in Supplementary Fig. 3. The 60ZP and the 70ZP glasses have almost identical $S_{\mathrm{PO}}(Q), S_{\mathrm{OO}}(Q)$ and $S_{\mathrm{ZnO}}(Q)$, indicating a

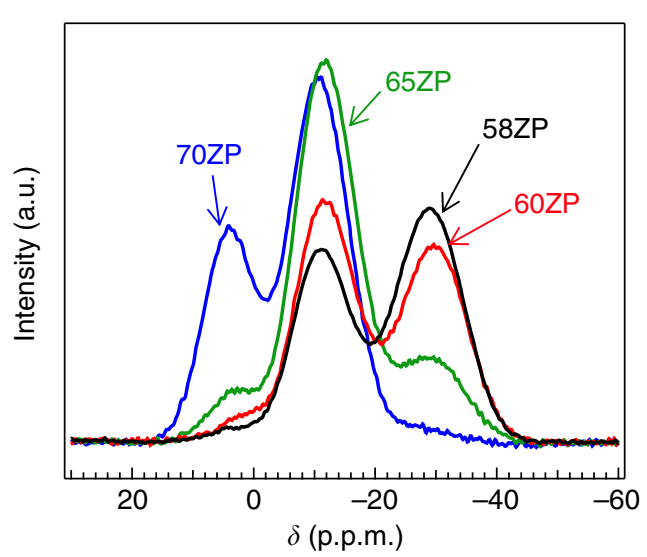

b

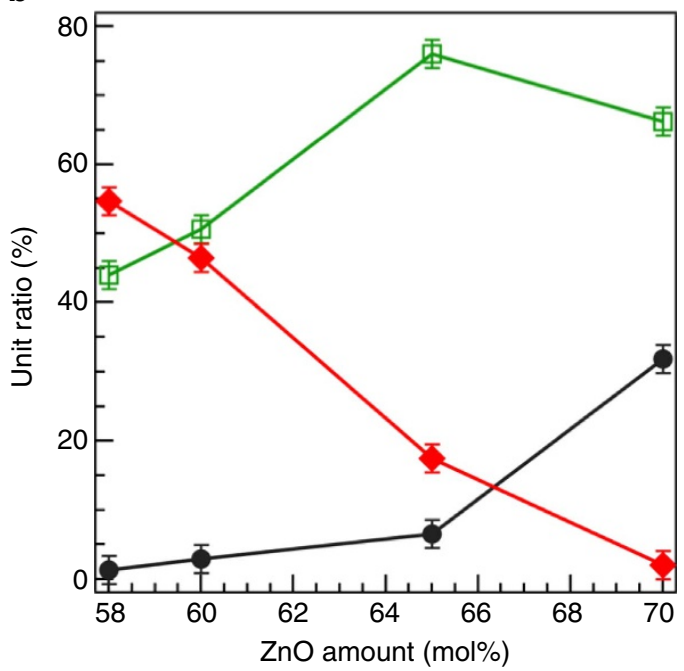

Figure $\left.2\right|^{\text {31P }}$ MAS NMR spectra of the ZP glass. (a) ${ }^{31} \mathrm{P}$ MAS NMR spectra and (b) $Q^{n}$ distribution. The peak areas are normalized using the amount of $\mathrm{P}_{2} \mathrm{O}_{5}$. The error bars in $\mathbf{b}$ represent s.d. of each peak area obtained from deconvolution of ${ }^{31} \mathrm{P}$ MAS NMR spectra.

that the different types of ZP glass have the same short-range structure. This similarity can also be clearly observed in the partial-pair correlation functions, $g_{i j}(r)$, shown in Supplementary Fig. 4. On the other hand, the $S_{\mathrm{PP}}(Q), S_{\mathrm{PZn}}(Q)$ and $S_{\mathrm{ZnZn}}(Q)$ differ significantly, indicating the substantial difference between the connectivity of the short-range structural units, $\mathrm{PO}_{4}$ tetrahedra and $\mathrm{Zn}-\mathrm{O}$ polyhedra in the 60ZP and the 70ZP glasses. This behaviour is consistent with the NMR data, which reveal a significant reduction of $\mathrm{Q}^{2}$ species in the 70ZP glass. In addition, $N_{\mathrm{ZnO}}$ of 3.6 and 3.8 were calculated at atomic distances of up to $2.4 \AA$ for $60 \mathrm{ZP}$ and $70 \mathrm{ZP}$ glasses, respectively. The $\mathrm{Zn}-\mathrm{O}$ coordination numbers obtained from RMC modelling agree with the data determined experimentally by EXAFS, which is very sensitive to the $\mathrm{Zn}-\mathrm{O}$ coordination, but are smaller than some of the values reported in previous studies ${ }^{34,37,38}$. To confirm the reduced $\mathrm{Zn}-\mathrm{O}$ coordination in the glass, the FT EXAFS spectra and neutron total correlation functions $T(r)$ for the different types of $\mathrm{ZP}$ glass were compared with those of $\mathrm{ZnO}$ and $\beta-\mathrm{Zn}_{2} \mathrm{P}_{2} \mathrm{O}_{7}$ crystals. As can be seen in Supplementary Fig. 5a, the $\mathrm{Zn}-\mathrm{O}$ atomic distance in FT EXAFS spectra of the ZP glass is slightly shorter than that of $\mathrm{ZnO}$ crystal. In addition, the $T(r)$ of $\beta$ $\mathrm{Zn}_{2} \mathrm{P}_{2} \mathrm{O}_{7}$ crystal shown in Supplementary Fig. $5 \mathrm{~b}$ has two $\mathrm{Zn}-\mathrm{O}$ atomic distances at $2.03 \AA(\mathrm{Zn}-\mathrm{O}(\mathrm{I}))$ and at $2.30 \AA(\mathrm{Zn}-\mathrm{O}(\mathrm{II}))$. The $N_{\mathrm{ZnO}}$ calculated up to the first and the second coordination distances are 4 and 2 , respectively. Thus, the correlation peak at 
$2.03 \AA$ of $T(r)$ for $\beta-\mathrm{Zn}_{2} \mathrm{P}_{2} \mathrm{O}_{7}$ crystal is assigned to tetrahedral coordinated zinc. On the other hand, the $\mathrm{Zn}-\mathrm{O}$ atomic distance is shorter and the peak area in the ZP glass is smaller than those in $\mathrm{ZnO}$ and $\beta-\mathrm{Zn}_{2} \mathrm{P}_{2} \mathrm{O}_{7}$ crystal. These observations above suggest that the $\mathrm{Zn}-\mathrm{O}$ coordination in $\mathrm{ZP}$ glass is different from that in $\mathrm{ZnO}$ and $\beta-\mathrm{Zn}_{2} \mathrm{P}_{2} \mathrm{O}_{7}$ crystal, although fourfold zinc is dominant in glasses as Walter et al. concluded ${ }^{30}$.

\section{Discussion}

Thus, we have succeeded in modelling atomic configurations, which reproduce the X-ray, neutron, EXAFS and NMR data. To understand network formation in the RMC models, the $\mathrm{Q}^{n}$
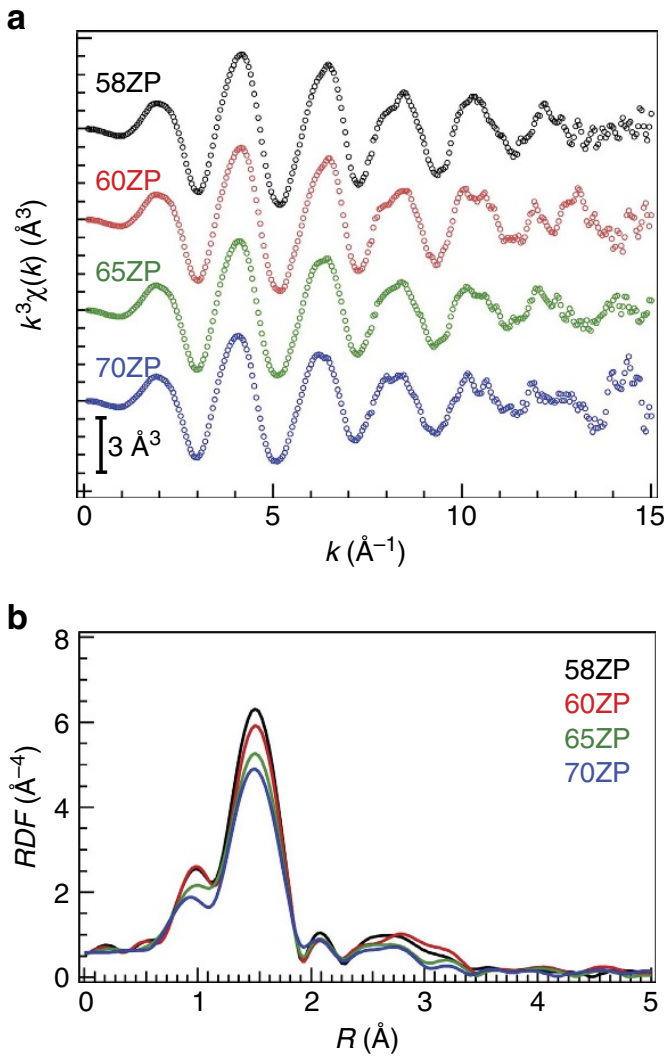

Figure 3 | EXAFS analysis of the ZP glass. (a) EXAFS spectra $k^{3} \chi(k)$ of the $\mathrm{ZnO}-\mathrm{P}_{2} \mathrm{O}_{5}$ glass and $(\mathbf{b})|\mathrm{FT}(R)|$ of the spectra. distribution was calculated on the basis of the atomic configurations obtained from said models. $\mathrm{Q}^{0}: \mathrm{Q}^{1}: \mathrm{Q}^{2}: \mathrm{Q}^{3}: \mathrm{Q}^{4}$ ratios of 0.8:49.8:49.0:0.4:0 and 33.8:65.8:0.4:0:0, obtained for the 60ZP and the 70ZP, respectively, concurred with the results of NMR shown in Fig. 2b and those reported in previous studies ${ }^{29-31,35}$. However, although Hoppe et al. reported on the structure of $\mathrm{ZP}$ glass derived from RMC modelling using X-ray and neutron diffraction data, we are not aware of any structure models that reproduce diffraction, EXAFS and NMR data. Accordingly, it is demonstrated that our model is reliable not at only short-range but also at intermediate range, including the connectivity of polyhedra, because our obtained $\mathrm{Q}^{n}$ distribution was calculated by analysing the $-\mathrm{O}-\mathrm{P}-\mathrm{O}-$ connectivity (not simply estimating on the basis of the coordination numbers reported in ref. 39 (see Methods for details)). The results of $\mathrm{Q}^{n}$ analysis and connectivity of atoms together with coordination numbers are listed in Supplementary Table 4. To understand the connectivity of the network consisting of $\mathrm{PO}_{4}$ tetrahedra and $\mathrm{Zn}-\mathrm{O}$ polyhedra in detail, oxygen-cation coordination number distributions were calculated, as shown in Fig. 5. As can be seen in Fig. 5a,b, it is found that $\mathrm{OP}_{2}$ is more dominant than $\mathrm{OZn}_{2}$ in $60 \mathrm{ZP}$ glass, while $\mathrm{OZn}_{2}$ is more dominant than $\mathrm{OP}_{2}$ in $70 \mathrm{ZP}$ glass, demonstrating that the role of network formation changes from $\mathrm{PO}_{4}$ tetrahedra to $\mathrm{Zn}-\mathrm{O}$ polyhedra between $60 \mathrm{ZP}$ and $70 \mathrm{ZP}$, although Fig. $5 \mathrm{c}$ suggests that twofold oxygen is taken by an interplay between the $\mathrm{PO}_{4}$ tetrahedra and $\mathrm{Zn}-\mathrm{O}$ polyhedra. The change in the role of the network formation from $\mathrm{PO}_{4}$ tetrahedra to $\mathrm{Zn}-\mathrm{O}$ polyhedra between 60ZP and 70ZP can explain the behaviour of the thermal expansion coefficient. It is also found that $33 \%$ of the oxygen is coordinated by three cations ( $9 \%$ is $\mathrm{P} 2-\mathrm{O}-\mathrm{Zn} 1$ and $24 \%$ is $\mathrm{P} 1-\mathrm{O}-\mathrm{Zn} 2)$ in $70 \mathrm{ZP}$ glass. Another important feature in oxygencation coordination is that the cation coordination numbers are increased in 70ZP glass. To understand such connectivity in $3 \mathrm{D}$ atomic configuration, the connectivity of $\mathrm{PO}_{4}$ and $\mathrm{Zn}-\mathrm{O}$ polyhedra were analysed. Figure 6 shows the 3D linkage of the phosphate network in terms of the chain length, as calculated from the total number of atoms in each phosphate; Fig. 6a shows the fraction of $\mathrm{Q}^{1}$ units and $\mathrm{Q}^{2}$ chains of $\mathrm{PO}_{4}$ polyhedra in the 60ZP glass and a typical RMC-modelled $\mathrm{Q}^{2}$ chain. As can be seen in Fig. 6b, the 70ZP glass consists of only isolated $\mathrm{PO}_{4}$ tetrahedra $\left(\mathrm{Q}^{0}\right)$ and $\mathrm{P}_{2} \mathrm{O}_{7}$ dimers $\left(\mathrm{Q}^{1}\right)$. Thus, our RMC models reproduce the modification of the $3 \mathrm{D}$ phosphate network as observed by ${ }^{31} \mathrm{P}$ MAS NMR. Similar behaviour is observed in binary silicate and aluminate glass with low glass-forming ability ${ }^{40-42}$. This observation is significant since low-melting-point phosphate glass is essential to many commercial applications.
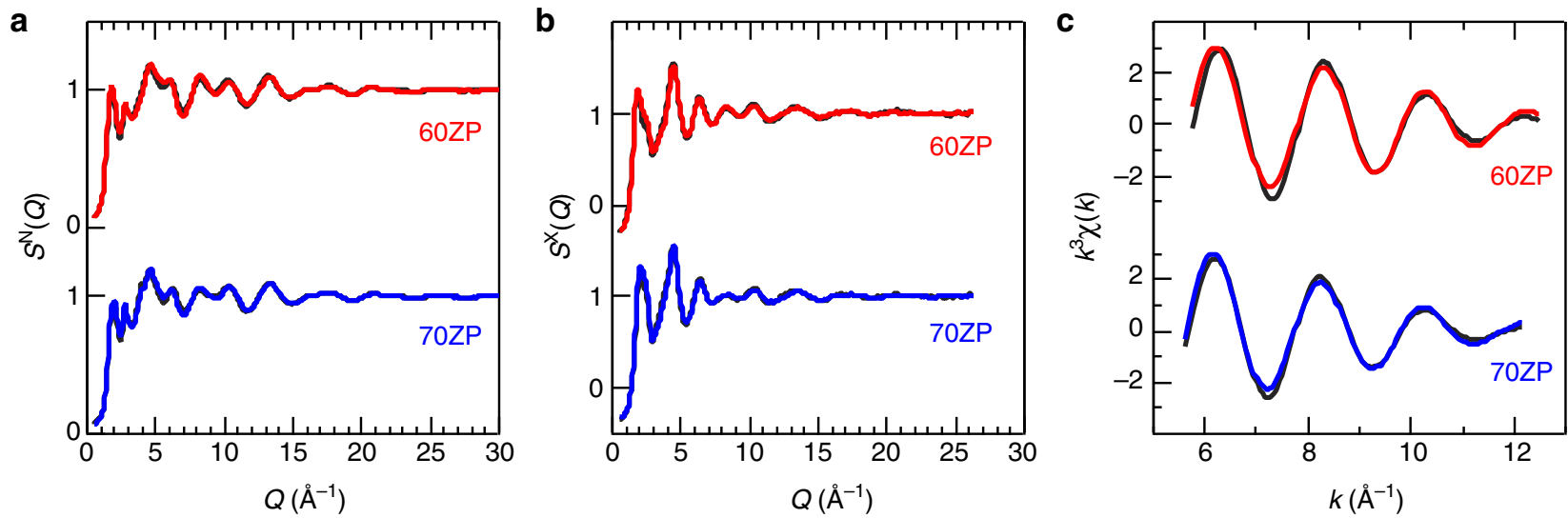

Figure 4 | Comparison between neutron/synchrotron X-ray data and RMC model for the ZP glass. (a) Neutron total structure factor $S^{\mathrm{N}}(Q)(\mathbf{b}) X$-ray total structure factor $S^{X}(Q)$ and $(\mathbf{c})$ EXAFS $k^{3} \chi(k)$. The EXAFS $k^{3} \chi(k)$ were obtained by back Fourier transformation of $|F T(R)|$ of the first correlation peak. Black curve, experimental data; coloured curve, RMC model. 
The probabilities of the formation of polyhedral connections between $\mathrm{PO}_{4}$ tetrahedra and $\mathrm{Zn}-\mathrm{O}$ polyhedra were calculated (Supplementary Table 5) to elucidate the mechanism of glass formation in binary oxide glass with low amounts of NWF. Corner-sharing between $\mathrm{PO}_{4}-\mathrm{PO}_{4}, \mathrm{PO}_{4}-\mathrm{Zn}-\mathrm{O}$ polyhedra and $\mathrm{Zn}-\mathrm{O}$ polyhedra-Zn-O polyhedra occurred predominantly, as stipulated by Zachariasen's rule ${ }^{1}$. Both types of ZP glass exhibit the same polyhedral connections, to which their similar $T_{\mathrm{g}}$ and longitudinal modulus can be attributed. Furthermore, the total number of atoms constituting the $\mathrm{Zn}_{x} \mathrm{O}_{y}$ units (Fig. 7) was estimated to determine the origin of the glass network in the glass. As the figure shows, the $\mathrm{Zn}_{x} \mathrm{O}_{y}$ units do not form a network in 60ZP glass, and the size of the fragment (consisting of up to 41 atoms, as shown in the inset of Fig. $7 \mathrm{a}$ ) is $<20 \AA$. In contrast, $10 \%$ of the $\mathrm{Zn}_{x} \mathrm{O}_{y}$ units in the 70ZP glass form networks consisting of more than 40 atoms, as manifested by their atomic configurations consisting of up to 1,300 atoms, as shown in the inset of Fig. $7 \mathrm{~b}$. The unusual network structure units formed by the $\mathrm{Zn}_{x} \mathrm{O}_{y}$ polyhedra can be attributed to the smaller oxygen coordination of the zinc compared to that of the $\mathrm{ZnO}$ crystal; the high glassforming ability of the 70ZP glass stems from this small oxygen coordination. Although the $\mathrm{Zn}-\mathrm{O}$ coordination number is larger in the RMC model recently reported by Hoppe et al. ${ }^{34}$, they attributed the increased oxygen coordination around the zinc to a

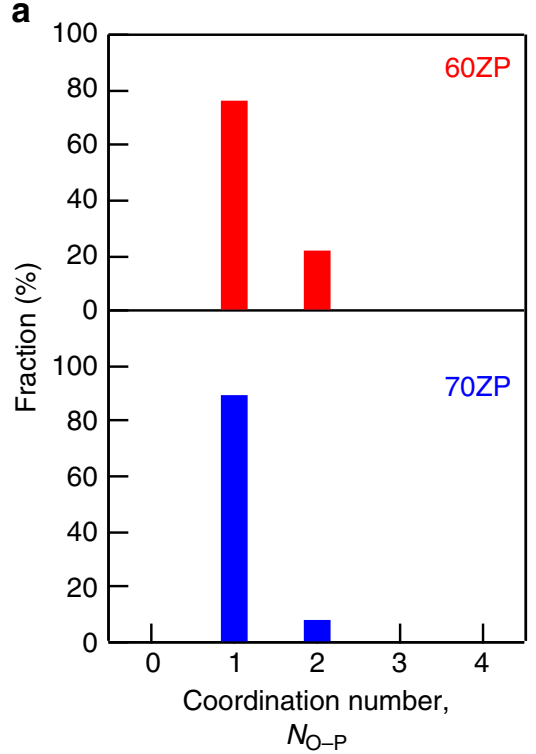

b

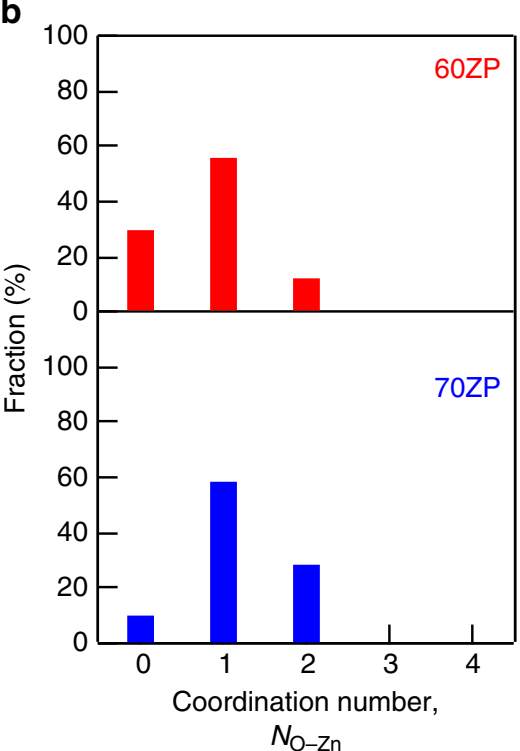

C

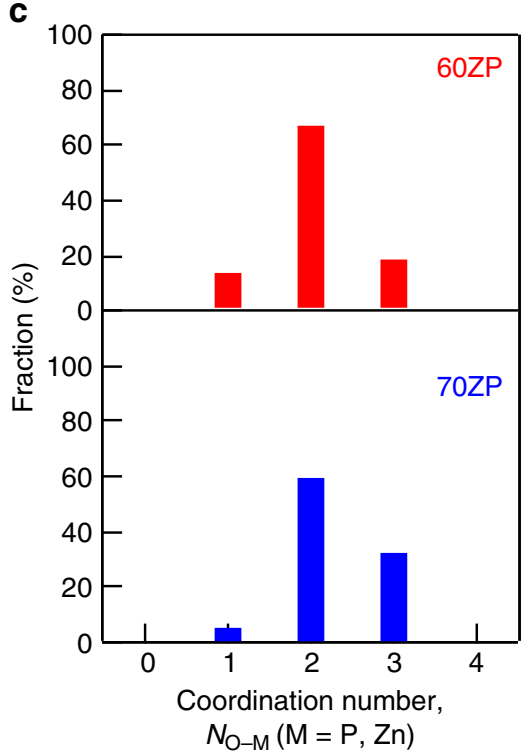

Figure 5 | Oxygen-cation coordination number distribution in the ZP glass. The coordination number distribution of (a) phosphorus, (b) zinc (c) cation (phosphorus and zinc) around oxygen.

a

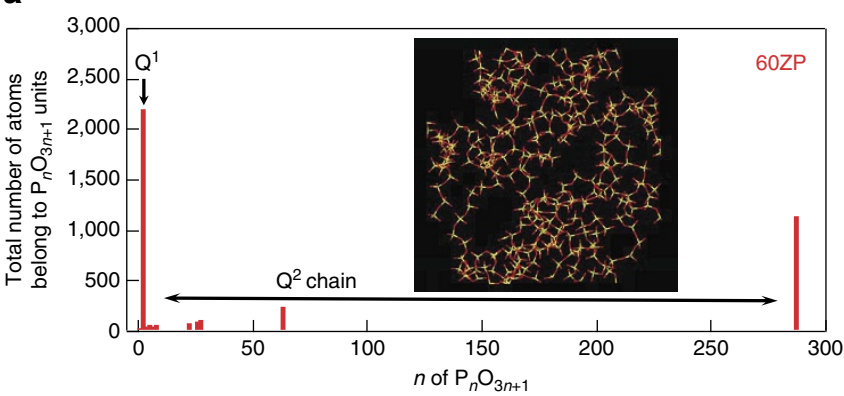

b

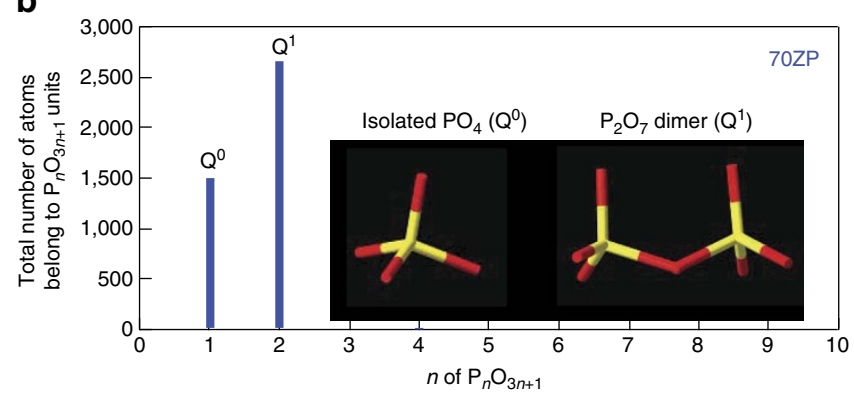

Figure 6 | Connectivity of $\mathrm{PO}_{\mathbf{4}}$ tetrahedra in the ZP glass. The size distribution of $\mathrm{PO}_{4}$ tetrahedral chains in $\mathbf{a} 60 \mathrm{ZP}$ glass and in $\mathbf{b} 70 \mathrm{ZP}$ glass. $\mathrm{P}$ and $\mathrm{O}$ atoms are shown in yellow and red colour, respectively. a

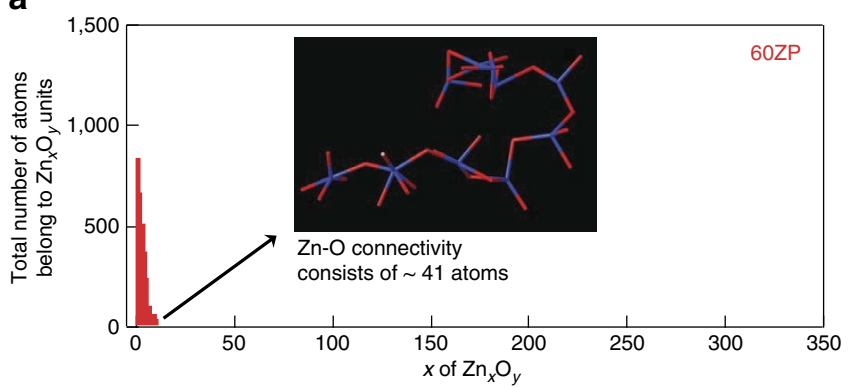

b

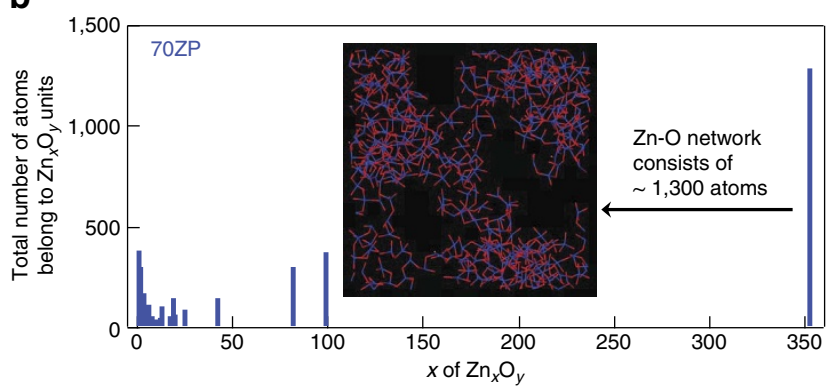

Figure 7 | Connectivity of $\mathbf{Z n}_{\mathbf{x}} \mathbf{O}_{\mathbf{y}}$ polyhedra in the $\mathbf{Z P}$ glass. The size distribution of $\mathrm{Zn}_{x} \mathrm{O}_{y}$ polyhedral chains in $\mathbf{a} 60 \mathrm{ZP}$ glass and in $\mathbf{b} 70 Z \mathrm{P}$ glass. $\mathrm{Zn}$ and $\mathrm{O}$ atoms are shown in blue and red colour, respectively. 
the increased rigidity of the $\mathrm{ZP}$ in the $75 \mathrm{ZP}$ and $80 \mathrm{ZP}$ glass. On the other hand, it is suggested from our RMC model that the small $\mathrm{Zn}-\mathrm{O}$ coordination is a signature of the NWF, according to Zachariasen's rule ${ }^{1}$, in our model for $70 \mathrm{ZP}$ glass. This suggestion is supported by the small oxygen-cation coordinations (2.06 in $60 \mathrm{ZP}$ and 2.29 in 70ZP) listed in Supplementary Table 4, although the oxygen-cation coordination number is increased in 70ZP glass.

In this study, several types of binary $\mathrm{ZnO}-\mathrm{P}_{2} \mathrm{O}_{5}$ glass are prepared with a wide range of chemical compositions. The present findings regarding the 3D network formation of $\mathrm{Zn}_{x} \mathrm{O}_{y}$ units suggest that interplay between the $\mathrm{PO}_{4}$ tetrahedra and $\mathrm{Zn}-\mathrm{O}$ polyhedra is important for tuning the physical properties of the glass. A small $\mathrm{Zn}-\mathrm{O}$ coordination number might be important for improving the glass-forming ability and to increase the elastic modulus owing to this interplay. On the other hand, the addition of $\mathrm{ZnO}$ results in an increased oxygen-cation coordination number, which indicates an increased glass transition temperature, refractive index and packing fraction, and hence longitudinal modulus. Furthermore, we find that the thermal expansion coefficient sensitively reflects the substitution of the phosphate chain network by a network consisting of $\mathrm{Zn}_{x} \mathrm{O}_{y}$ units in zinc-rich glass. In other words, we succeed in revealing, for the first time, the relationship between the atomic structure of glass and its functionality by using structural modelling based on a combination of an advanced quantum beam technique and spectroscopic measurement. Since phosphate glass exhibits a low melting point, then both the phosphate and glass networks consist of counter metal oxides, which give rise to this lowmelting-point behaviour. The results obtained in this study, via several structural analysis methods, are significant since they clearly reveal the fundamental properties that determine the functionality of these types of glasses and may be useful in the design of phosphate glasses for practical applications.

\section{Methods}

Preparation of binary ZP glass. The different types of binary $\mathrm{ZnO}-\mathrm{P}_{2} \mathrm{O}_{5}(x \mathrm{ZP})$ glass, namely, $58 \mathrm{ZnO}-42 \mathrm{P}_{2} \mathrm{O}_{5}(58 \mathrm{ZP}), 60 \mathrm{ZnO}-40 \mathrm{P}_{2} \mathrm{O}_{5}(60 \mathrm{ZP}), 65 \mathrm{ZnO}-35 \mathrm{P}_{2} \mathrm{O}_{5}$ (65ZP) and $70 \mathrm{ZnO}-30 \mathrm{P}_{2} \mathrm{O}_{5}(70 \mathrm{ZP})$, were prepared by a conventional meltquenching method using a platinum crucible ${ }^{47}$. Batches consisting of $\mathrm{ZnO}$ $(99.99 \%)$ and $\left(\mathrm{NH}_{4}\right)_{2} \mathrm{HPO}_{4}(99 \%)$ were initially calcined at $800^{\circ} \mathrm{C}$ for $3 \mathrm{~h}$ in an ambient atmosphere. The calcined solid was then melted at $1,100^{\circ} \mathrm{C}$ for $30 \mathrm{~min}$ in an ambient atmosphere. The glass melt was quenched on a stainless plate maintained at $200^{\circ} \mathrm{C}$ and then annealed at the glass transition temperature, $T_{\mathrm{g}}$, for $1 \mathrm{~h}$. The samples were then mechanically polished to produce a mirror surface.

Compositional analysis. Chemical compositions of ZP glasses were determined by using inductively coupled plasma-atomic emission spectrometry analysis using a SPECTRO BLUE (SPECTRO, Germany). The standard solutions (1,5,10 and 15 p.p.m.) of each element for the calibration curves were prepared by mixing each 1,000 p.p.m. standard solution with $0.1 \mathrm{M} \mathrm{HNO}_{3}$ solution. The calibration curves at different wavelengths of each element are shown in Supplementary Fig. 1. It was found that the calibration curves show a good linearly for both $\mathrm{Zn}$ and P. The concentrations of zinc and phosphorus are calculated by using averaged values of these three emission bands shown in Supplementary Fig. 1. The measured concentration values are summarized in Supplementary Table 1. The $\mathrm{ZnO}$ fraction $f_{\mathrm{ZnO}}$ of the glasses, that is, chemical composition of $\mathrm{ZnO}-\mathrm{P}_{2} \mathrm{O}_{5}$ glasses, can be obtained from both concentration of $\mathrm{Zn}, c_{\mathrm{Zn}}$, and that of $\mathrm{P}, c_{\mathrm{P}}$, by using the following equation:

$$
f_{\mathrm{ZnO}}=c_{\mathrm{Zn}} /\left(c_{\mathrm{Zn}}+\left(c_{\mathrm{P}} / 2\right)\right) \times 100
$$

From two samples of each composition, average $\mathrm{ZnO}$ fraction can be calculated.

Physicochemical analysis. The $T_{\mathrm{g}}$ was determined from thermomechanical analysis (TMA) at a heating rate of $10^{\circ} \mathrm{C} \mathrm{min}^{-1}$ and under a $1.0 \mathrm{~g}$ loading using a TMA 8310 (Rigaku, Japan). The linear thermal expansion coefficient of the samples, measuring around $4 \mathrm{~mm} \times 4 \mathrm{~mm} \times 15 \mathrm{~mm}$, was also evaluated using the same equipment at a temperature range of $200-350^{\circ} \mathrm{C}$. Moreover, the local coordination state of phosphorus was determined by measuring the ${ }^{31} \mathrm{P}$ MAS
NMR spectra using a CMX-400 NMR spectrometer (JEOL, Japan). A frequency, spin rate and pulse delay of $161.80 \mathrm{MHz}, 10 \mathrm{kHz}$ and $5 \mathrm{~s}$, respectively, were used in the measurements. The chemical shifts were estimated with respect to $\mathrm{H}_{3} \mathrm{PO}_{4}$ in a $\mathrm{D}_{2} \mathrm{O}$ solution (0 p.p.m.) and the conventional notation for phosphorus sites, $\mathrm{Q}^{n}$, was used for the analysis. The $n$ value denotes the number of bridging oxygens per $\mathrm{PO}_{4}$ tetrahedron. Furthermore, the densities were measured by applying the Archimedes method using water at room temperature. We measured the refractive index of the samples using a prism coupler with a $473,633,1,319$ and $1,553 \mathrm{~nm}$ light source (Metericon, NJ, USA); the error in the measurement was $10^{-4}$.

Elastic modulus measurement. The Brillouin shifts $v_{\mathrm{B}}$ of the different types of glass were measured using a high-resolution modification of a Sandercock Fabry-Perot system ${ }^{48}$. A frequency-doubled diode-pumped solid state neodymium:yttrium-aluminium-garnet laser oscillating in a single longitudinal mode at $532 \mathrm{~nm}$ (Oxxius SLIM-532 $300 \mathrm{~mW}$ ) was used as the excitation source. In addition to the excitation laser source, a second weak reference laser was also used to act as an independent reference signal that was used for stabilization of the Fabry-Perot. The reference laser was a small diode-pumped solid state neodymium:yttrium-vanadate $\left(\mathrm{Nd}: \mathrm{YVO}_{4}\right)$ laser module (Photonic Products 300-0088-01, $4 \mathrm{~mW}$ ) oscillating in single transverse mode (TEM00), which had two to three longitudinal modes separated by $120 \mathrm{GHz}$. The longitudinal sound velocity $V_{\mathrm{L}}$, shown in Supplementary Table 2, was calculated from $V_{\mathrm{L}}=v_{\mathrm{B}} \lambda / 2 n_{532}$, where $v_{\mathrm{B}}, \lambda$ and $n_{532}$ are the Brillouin shift, the wavelength of incident light (=532 nm) and the refractive index at $532 \mathrm{~nm}$, respectively. The $n_{532}$ values were calculated from the Cauchy relationship between the refractive indices at different wavelengths.

EXAFS measurement. The $\mathrm{Zn} K$-edge $(9.66 \mathrm{keV})$ EXAFS spectra were measured at the BL01B1 beamline of SPring- 8 synchrotron radiation facility (Hyogo, Japan). The measurements were performed using a Si (111) double-crystal monochromator in the transmission mode (Quick Scan method) at room temperature. Pellet samples for the measurements were prepared by mixing the granular sample with boron nitride. The corresponding analyses were performed by using REX2000 software (Rigaku) ${ }^{49}$.

High-energy X-ray diffraction measurement. The high-energy X-ray diffraction experiment was performed at the BL04B2 beamline at the SPring- 8 synchrotron radiation facility, using a two-axis diffractometer dedicated to the study of disordered materials ${ }^{50}$. The energy of the incident X-rays was $61.4 \mathrm{keV}$. The raw data were corrected for polarization, absorption and the background, and the contribution of Compton scattering was subtracted by using standard data analysis software ${ }^{50}$.

RMC modelling. RMC modelling of the 60ZP and the 70ZP glass was performed using RMC ++ code $^{51}$. The start configurations, which contained 5,000 and 5,250 particles for the 60ZP and the 70ZP, respectively, were created using hard-sphere Monte Carlo simulations with constraints applied to avoid physically unrealistic structures. The $r$-spacing for the calculations of partial-pair correlation functions was set to be $0.05 \AA$. Two kinds of constraints were used: a closest atom-atom approach and connectivity. The closest atom-atom approach was chosen based on the need to avoid unreasonable spikes in the partial-pair correlation functions. The constraint on the $\mathrm{P}-\mathrm{O}$ connectivity was that all of the phosphorus atoms were coordinated to four oxygen atoms for atomic distances of up to $1.7 \AA$. In addition, fixed neighbour constraints ${ }^{52}$ were applied for $\mathrm{P}-\mathrm{O}$ at $1.55-1.7 \AA$ and $\mathrm{P}=\mathrm{O}$ at 1.4-1.55 $\AA$ to reproduce the $\mathrm{Q}^{0}: \mathrm{Q}^{1}: \mathrm{Q}^{2}: \mathrm{Q}^{3}$ ratio based on the results of the NMR in which the $\mathrm{Q}^{0}: \mathrm{Q}^{1}: \mathrm{Q}^{2}: \mathrm{Q}^{3}$ ratio is $0: 50: 50: 0$ for $60 \mathrm{ZP}$ and 33.3:66.7:0:0 for 70ZP. After the hard-sphere Monte Carlo simulations, RMC simulations containing X-ray $S(Q)$, neutron $S(Q)$ and $k^{3} \chi(k)$ EXAFS data, measured at the $\mathrm{Zn} K$-edge, were performed. The EXAFS back scattering tables were obtained from FEFF calculations $^{53}$.

Data availability. The authors declare that all relevant data supporting the findings of this study are available from the corresponding authors on request.

\section{References}

1. Zachariasen, W. H. The atomic arrangement in glass. J. Am. Chem. Soc. 54, 3841-3851 (1932).

2. Warren, B. E. \& Biscoe, J. The structure of silica glass by X-ray diffraction studies. J. Am. Ceram. Soc. 21, 49-54 (1938).

3. Du, J. \& Cormack, A. N. The medium range structure of sodium silicate glasses: a molecular dynamics simulation. J. Non-Cryst. Solids 349, 66-79 (2004).

4. Du, J. \& Corrales, L. R. First sharp diffraction peak in silicate glasses: structure and scattering length dependence. Phys. Rev. B 72, 092201 (2005). 
5. Du, J. \& Corrales, L. R. Compositional dependence of the first sharp diffraction peaks in alkali silicate glasses: a molecular dynamics study. J. Non-Cryst. Solids 352, 3255-3269 (2006).

6. Pedone, A., Malavasi, G., Cormack, A. N., Segre, U. \& Menziani, M. C. Insight into elastic properties of binary alkali silicate glasses; prediction and interpretation through atomistic simulation techniques. Chem. Mater. 19, 3144-3154 (2007).

7. Brow, R. K. Review: the structure of simple phosphate glasses. J. Non-Cryst. Solids 263-264, 1-28 (2000)

8. Martin, S. W. Review of the structure of phosphate glasses. Euro. J. Solid State Inorg. Chem. 28, 163-205 (1991).

9. Hoppe, U. A structural model for phosphate glasses. J. Non-Cryst. Solids 195, 138-147 (1996).

10. Sayer, M. \& Mansingh, A. Transport properties of semiconducting phosphate glasses. Phys. Rev. B 6, 4629-4643 (1972).

11. Masai, H. et al. ${ }^{31} \mathrm{P}$ NMR and IR study of highly water-stable $\mathrm{SrO}-\mathrm{BaO}-\mathrm{Nb}_{2} \mathrm{O}_{5}-\mathrm{P}_{2} \mathrm{O}_{5}$ glass and glass-ceramics. Chem. Lett. 42, 1305-1307 (2013).

12. Takamatsu, $\mathrm{Y}$. et al. The state of $\mathrm{P}=\mathrm{O}_{\mathrm{nb}}$ non-bridging oxygen and proton incorporation in binary $\mathrm{MO} \cdot \mathrm{P}_{2} \mathrm{O}_{5}(\mathrm{M}=\mathrm{Ca}, \mathrm{Mg})$ phosphate glasses. Solid State Ionics 245-246, 19-23 (2013).

13. Bunker, B. C., Arnold, G. W. \& Wilder, J. A. Phosphate glass dissolution in aqueous solutions. J. Non-Cryst. Solids 64, 291-316 (1984).

14. Kokubo, T. \& Takadama, H. How useful is SBF in predicting in vivo bone bioactivity? Biomaterials 27, 2907-2915 (2006).

15. Paulose, P. I., Jose, G., Thomas, V., Unnikrishnan, N. V. \& Warrier, M. K. R. Sensitized fluorescence of $\mathrm{Ce}^{3+} / \mathrm{Mn}^{2+}$ system in phosphate glass. J. Phys. Chem. Solids 64, 841-846 (2003).

16. Campbell, J. H. \& Suratwala, T. I. Nd-doped phosphate glasses for high-energy/ high-peak-power lasers. J. Non-Cryst. Solids 263, 318-341 (2000).

17. Yan, Y. C., Faber, A. J., de Waal, H., Kik, P. G. \& Polman, A. Erbium-doped phosphate glass waveguide on silicon with $4.1 \mathrm{~dB} / \mathrm{cm}$ gain at $1.535 \mu \mathrm{m}$. Appl. Phys. Lett. 71, 2922-2924 (1997).

18. Inaba, S., Hosono, H. \& Ito, S. Entropic shrinkage of an oxide glass. Nat. Mater. 14, 312-317 (2015)

19. Brow, R. K. \& Tallant, D. R. Structural design of sealing glasses. J. Non-Cryst. Solids 222, 396-406 (1997).

20. Morena, R. Phosphate glasses as alternatives to Pb-based sealing frits. J. NonCryst. Solids 263-264, 382-387 (2000)

21. Joshi, B. C. Enhanced $\mathrm{Eu}^{3+}$ emission by nonradiative energy-transfer from $\mathrm{Tb}^{3+}$ in zinc phosphate glass. J. Non-Cryst. Solids 180, 217-220 (1995).

22. Caldino, U., Hernandez-Pozos, J. L., Flores, C., Speghini, A. \& Bettinelli, M. Photoluminescence of $\mathrm{Ce}^{3+}$ and $\mathrm{Mn}^{2+}$ in zinc metaphosphate glasses. J. Phys.: Condens. Matter 17, 7297-7305 (2005).

23. Masai, H., Takahashi, Y., Fujiwara, T., Matsumoto, S. \& Yoko, T. High photoluminescent property of low-melting Sn-doped phosphate glass. Appl. Phys. Express 3, 082102 (2010).

24. Masai, H. et al. White light emission of Mn-doped $\mathrm{SnO}-\mathrm{ZnO}-\mathrm{P}_{2} \mathrm{O}_{5}$ glass containing no rare earth cation. Opt. Lett. 36, 2868-2870 (2011).

25. Masai, H. et al. Correlation between emission property and concentration of $\mathrm{Sn}^{2+}$ centre in the $\mathrm{SnO}-\mathrm{ZnO}-\mathrm{P}_{2} \mathrm{O}_{5}$ glass. Opt. Express 20, 27319-27326 (2012).

26. Özgür, Ü. A comprehensive review of $\mathrm{ZnO}$ materials and devices. J. Appl. Phys. 98, 041301 (2005).

27. Onyiriuka, E. C. Zinc phosphate glass surfaces studied by XPS. J. Non-Cryst. Solids 163, 268-273 (1993).

28. Brow, R. K. An XPS study of oxygen bonding in zinc phosphate and zinc borophosphate glasses. J. Non-Cryst. Solids 194, 267-273 (1996).

29. Brow, R. K., Tallant, D. R., Myers, S. T. \& Phifer, C. C. The short-range structure of zinc polyphosphate glass. J. Non-Cryst. Solids 191, 45-55 (1995).

30. Walter, G., Hoppe, U., Vogel, J., Carl, G. \& Hartmann, P. The structure of zinc polyphosphate glass studied by diffraction methods and ${ }^{31} \mathrm{P}$ NMR. J. NonCryst. Solids 333, 252-262 (2004).

31. Wiench, J. W., Pruski, M., Tischendorf, B., Otaigbe, J. U. \& Sales, B. C. Structural studies of zinc polyphosphate glasses by nuclear magnetic resonance. J. Non-Cryst. Solids 263-264, 101-110 (2000).

32. Hoppe, U. et al. Combined neutron and X-ray scattering study of phosphate glasses. J. Non-Cryst. Solids 293-295, 158-168 (2001).

33. Walter, G., Hoppe, U., Baade, T., Kranold, R. \& Stachel, D. Intermediate range order in MeO- $\mathrm{P}_{2} \mathrm{O}_{5}$ glasses. J. Non-Cryst. Solids 217, 299-307 (1997).

34. Hoppe, U., Dimitriev, Y. \& Jóvári, P. Structure of zinc phosphate glasses of 75 and $80 \mathrm{~mole} \% \mathrm{ZnO}$ content studied by X-ray diffraction and reverse Monte Carlo simulations. Z. Naturforsch. A 60, 517-526 (2005).

35. Tischendorf, B., Otaigbe, J. U., Wiench, J. W., Pruski, M. \& Sales, B. C. A study of short and intermediate range order in zinc phosphate glasses. J. Non-Cryst. Solids 282, 147-158 (2001).

36. Saout, G. L. et al. A multispectroscopic study of $\mathrm{PbO}_{x} \mathrm{ZnO}_{0.6-x}\left(\mathrm{P}_{2} \mathrm{O}_{5}\right)_{0.4}$ glasses. J. Non-Cryst. Solids 293-295, 657-662 (2001).

37. Tischendorf, B., Alam, T. M., Cygan, R. T. \& Otaigbe, J. U. The structure and properties of binary zinc phosphate glasses studied by molecular dynamics simulations. J. Non-Cryst. Solids 316, 261-272 (2003).
38. Suzuya, K., Itoh, K., Kajinami, A. \& Loong, C.-K. The structure of binary zinc phosphate glasses. J. Non-Cryst. Solids 345, 80-87 (2004).

39. Hoppe, U., Walter, G., Carl, G., Neuefeind, J. \& Hannon, A. C. Structure of zinc phosphate glasses probed by neutron and X-ray diffraction of high resolving power and by reverse Monte Carlo simulations. J. Non-Cryst. Solids 351, 1020-1031 (2005).

40. Kohara, S. et al. Glass formation at the limit of insufficient network formers. Science 303, 1649-1652 (2004).

41. Kohara, S. et al. Relationship between topological order and glass forming ability in densely packed enstatite and forsterite composition glasses. Proc. Natl Acad. Sci. USA 108, 14780-14785 (2011).

42. Akola, J. et al. Network topology for the formation of solvated electrons in binary $\mathrm{CaO}-\mathrm{Al}_{2} \mathrm{O}_{3}$ composition glasses. Proc. Natl Acad. Sci. USA 110, 10129-10134 (2013).

43. Kohara, S. et al. Atomic and electronic structures of an extremely fragile liquid. Nat. Commun. 5, 5892 (2014).

44. Tomozawa, M., Takata, M., Acocella, J., Watson, E. B. \& Takamori, T. Thermal properties of $\mathrm{Na}_{2} \mathrm{O}-3 \mathrm{SiO}_{2}$ glasses with high water content. J. Non-Cryst. Solids 56, 343-348 (1983).

45. Shelby, J. E. Thermal expansion of alkali borate glasses. J. Am. Ceram. Soc. 66, 225-227 (1983).

46. Kirkpatrick, R. J. \& Brow, R. K. Nuclear magnetic resonance investigation of the structures of phosphate and phosphate-containing glasses: a review. Solid State Nucl. Mag. 5, 9-21 (1995).

47. Masai, H. et al. Fabrication of Sn-doped zinc phosphate glass using a platinum crucible. J. Non-Cryst. Solids 358, 265-269 (2012).

48. Koreeda, A. \& Saikan, S. Note: higher resolution Brillouin spectroscopy by offset stabilization of a tandem Fabry-Pérot interferometer. Rev. Sci. Instrum 82, 126103 (2011).

49. Taguchi, T., Ozawa, T. \& Yashiro, H. REX2000: yet another XAFS analysis package. Phys. Scripta T115, 205-206 (2005).

50. Kohara, S. et al. Structural studies of disordered materials using high-energy $\mathrm{x}$-ray diffraction from ambient to extreme conditions. J. Phys. Condens. Matter 19, 506101 (2007).

51. Gereben, O., Jóvári, P., Temleitner, L. \& Pusztai, L. A new version of the $\mathrm{RMC}^{+}+$, reverse Monte Carlo programme, aimed at investigating the structure of covalent glasses. J. Optoelectron. Adv. Mater. 9, 3021-3027 (2007).

52. Evrard, G. \& Pusztai, L. Reverse Monte Carlo modelling of the structure of disordered materials with RMC ++ : a new implementation of the algorithm in C ++ . J. Phys. Condens. Matter 17, S1-S13 (2005).

53. Ankudinov, A. L., Ravel, B., Rehr, J. J. \& Conradson, S. D. Real-space multiplescattering calculation and interpretation of X-ray-absorption near-edge structure. Phys. Rev. B 58, 7565-7576 (1998).

\section{Acknowledgements}

This work was partially supported by the JSPS KAKENHI Grant-in-Aid for Young Scientists (A) Number 26709048, the Izumi Science and Technology Foundation and the Collaborative Research Program of I.C.R., Kyoto University (grant Nos. 2015-69 and 2016-47). We thank Prof Y. Sohrin, Dr T. Minami and Mr M. Tsujisaka (I.C.R., Kyoto University) for supporting the inductively coupled plasma-atomic emission spectrometry measurement. The synchrotron radiation experiments were performed at the BL01B1 and the BL04B2 of SPring-8 with the approval of the Japan Synchrotron Radiation Research Institute (JASRI; Proposal Nos. 2013A1412, 2014A1134, 2015A1311, 2016A0130 and 2016A0134). We thank Dr T. Ina for supporting the EXAFS measurements at the BL01B1. This work was also supported by JST-PRESTO 'Advanced Materials Informatics through Comprehensive Integration among Theoretical, Experimental, Computational and Data-Centric Sciences' (JPMJPR15N4) and the 'Materials Research by Information Integration' Initiative (MI2I) project of the Support Program for Starting Up Innovation Hub from JST. We gratefully acknowledge Dr K. Suzuya for providing us with the neutron diffraction data for $\mathrm{ZnO}-\mathrm{P}_{2} \mathrm{O}_{5}$.

\section{Author contributions}

H.M. and S.K. formulated the research project; H.M. and S.O. performed the materials preparation and EXAFS analysis; H.M. and A.K. measured the elastic modulus using Brillouin scattering; H.M. performed the thermal expansion, refractive index and inductively coupled plasma-atomic emission spectrometry measurements; T.O. measured ${ }^{31}$ P MAS NMR spectra and analysed the resulting data; S.K. performed X-ray diffraction measurements and analysed the resulting data; Y.O. and S.K. performed RMC modelling; Y.O., H.M. and S.K. wrote the paper.

\section{Additional information}

Supplementary Information accompanies this paper at http://www.nature.com/ naturecommunications

Competing interests: The authors declare no competing financial interests. 
Reprints and permission information is available online at http://npg.nature.com/ reprintsandpermissions/

How to cite this article: Onodera, Y. et al. Formation of metallic cation-oxygen network for anomalous thermal expansion coefficients in binary phosphate glass.

Nat. Commun. 8, 15449 doi: 10.1038/ncomms15449 (2017).

Publisher's note: Springer Nature remains neutral with regard to jurisdictional claims in published maps and institutional affiliations. (c) (i) This work is licensed under a Creative Commons Attribution 4.0 International License. The images or other third party material in this article are included in the article's Creative Commons license, unless indicated otherwise in the credit line; if the material is not included under the Creative Commons license, users will need to obtain permission from the license holder to reproduce the material. To view a copy of this license, visit http://creativecommons.org/licenses/by/4.0/

(C) The Author(s) 2017 